\section{Protestas sociales por la salud en Colombia: la lucha por el derecho fundamental a la salud, 1994-2010}

\author{
Public demonstrations for health as a fundamental \\ human right in Colombia: 1994-2010
}

Protestos sociais pela saúde na Colômbia: a luta
pelo direito fundamental à saúde, 1994-2010

\begin{abstract}
This study reconstructs the health struggle in Colombia during implementation of the health reform from 1994 to 2010, based on an analysis of primary and secondary sources. The study focus is political struggle, a theory of collective action based on a relational perspective between collective actors and the political structure to comprehend historical transformations. Three episodes in the struggle are reconstructed, revealing a causal link between protests and structural reforms in social and health policy. The struggles by subordinate actors highlighted the dispossession of labor rights, crisis in public hospitals, and access barriers to services as adverse effects of the reform, even while government favored private capital interests. The protests continued despite anti-union violence and government crackdown, while new actors and a national health movement reshaped the public sphere, building an identity around the struggle for the fundamental right to health.
\end{abstract}

Right to Health; Health Care Reform;

Health Policy
María Esperanza Echeverry-López 1 Yadira Eugenia Borrero-Ramírez 2

\section{Resumen}

Esta investigación documental reconstruye la contienda transgresiva en salud en Colombia durante la implantación de la reforma, entre 1994 y 2010, a partir del análisis de fuentes primarias y secundarias. Utiliza el enfoque de la contienda política, una teoría de la acción colectiva, basada en una perspectiva relacional entre actores colectivos y estructura política, para comprender transformaciones históricas. Se reconstruyen tres episodios de contienda, evidenciando un vínculo causal entre protesta y reformas estructurales de política social y de salud. Las luchas de los actores subalternos visibilizaron el despojo de derechos laborales, la crisis de los hospitales públicos y las barreras de acceso a los servicios, como efectos adversos de la reforma; el gobierno favoreció los intereses del capital privado. Las protestas persistieron, pese a la violencia antisindical y a la represión gubernamental, nuevos actores y un movimiento nacional por la salud reconfiguraron la esfera pública, construyendo identidad en torno a la lucha por el derecho fundamental a la salud.

Derecho a la Salud; Reforma de la Atención de Salud; Política de Salud 


\section{Presentación}

Esta investigación documental reconstruye la contienda por la salud en Colombia, durante el proceso de implantación de la reforma a la salud, entre 1994 y 2010, a través de las protestas sociales realizadas por los actores subalternos. Para el efecto, inicialmente, aborda una síntesis del contexto, atravesado por dos tendencias antagónicas sobre el modelo de desarrollo y el derecho a la salud; luego presenta los conceptos teóricos y la metodología; posteriormente, los resultados describen las primeras protestas y los tres episodios de contienda encontrados. Finalmente, se presentan las conclusiones.

\section{El contexto: la contienda entre reforma a la salud y Estado Social de Derecho}

La contienda en salud en Colombia, durante las dos últimas décadas, está marcada por dos tendencias antagónicas, la hegemónica, de reforma de mercado en salud centrada en "un derecho" ligado a la capacidad de pago; y la del frágil Estado Social de Derecho (ESD), basada en la garantía del derecho fundamental a la salud.

El Sistema General de Seguridad Social en Salud (SGSSS) colombiano, creado con la Ley $n$. 100/93, es la expresión institucional del proceso de reforma a la salud, aún en curso, basado en el modelo de "mercado regulado", inspirado en la competencia administrada norteamericana 1 , reelaborada como "pluralismo estructurado" por Londoño \& Frenk 2; se inscribe en las reformas del Estado y de la política social implantadas en América Latina desde los ochenta, en medio de la crisis de la deuda externa, y en el marco del reordenamiento mundial del capital para enfrentar, con el modelo de acumulación neoliberal, la crisis mundial de mediados de los setenta ${ }^{3}$. En ese escenario, los organismos multilaterales -Banco Mundial (BM), Fondo Monetario Internacional (FMI) y Banco Interamericano de Desarrollo (BID)- argumentaban que la protección y regulación del mercado interno, y la intervención social del frágil e ineficiente Estado de Bienestar en la región restringían la competitividad, la iniciativa individual y la inversión privada, impidiendo el crecimiento económico 4

El Consenso de Washington en 1989 recoge esos planteamientos y propone, entre otras políticas de ajuste estructural (PAE), recortes al gasto público, privatización de empresas públicas, desregulación y protección de derechos de propiedad 5; incorporadas en varios documentos del BM como directrices impositivas de las reformas a la salud en América Latina, inicialmente, con 4 estrategias: participación de los usuarios en la financiación de los servicios, focalización del gasto social con subsidios a los más pobres, el seguro como protección del riesgo económico y la descentralización para trasladar gastos del nivel nacional al local 6, luego con paquetes de servicios costo-eficientes para disminuir la carga de enfermedad $7, y$, posteriormente, con la profundización de la focalización y de la transformación de subsidios de oferta en subsidios a la demanda 8 .

En la reforma a la salud colombiana, esas directrices del BM se traducen en un SGSSS basado en el aseguramiento con dos regímenes: el subsidiado para la población más pobre -seleccionada por focalización es financiado por el Estado y por los trabajadores cotizantes de más altos ingresos; el contributivo para los trabajadores con capacidad de pago y su familia. En ambos regímenes, los usuarios -según su clasificación económica y la frecuencia de uso- realizan copagos por la utilización de los servicios. El Plan Obligatorio de Salud (POS), amparado por el seguro, cubre servicios curativos con criterio costo-eficiente y servicios individuales de promoción y prevención. Las acciones colectivas de salud pública son obligatorias, universales, gratuitas y a cargo del Estado; mientras aseguradores y prestadores compiten por servicios curativos en el mercado. Las aseguradoras o empresas promotoras de salud (EPS) reciben una prima anual por afiliado, y son intermediarias, porque contratan los servicios con las instituciones prestadoras de servicios (IPS). Los hospitales públicos debieron transformarse en empresas sociales del estado, financieramente autosostenibles 9 .

En contraste, precedida de una tendencia hacia la democratización en América Latina y, de amplias luchas sociales en Colombia, como resultado de un pacto social, se formula una nueva Constitución Política (CP) en 1991, con el ESD como principio fundamental, éste implica realización universal de los derechos sociales como derechos fundamentales garantizados por el Estado 10. Para el efecto, la CP estableció la transferencia creciente de recursos económicos para la política social, desde el gobierno central hacia las entidades territoriales; creó instituciones de protección de los derechos -la Defensoría del Pueblo-, una Corte Constitucional, y la Acción de Tutela para la exigibilidad jurídica de los derechos fundamentales. Sin embargo, consideró a la salud como derecho fundamental sólo para los menores.

Las dos tendencias atraviesan la contienda política en el campo de la salud. Por un lado, siguiendo los acuerdos con los organismos financieros internacionales, las transformaciones 
estructurales del Estado y de la política social devinieron en reformas laborales, a la seguridad social y a la educación, con desmantelamiento sindical y de las instituciones públicas, y despidos masivos de trabajadores 4 . En salud, los defensores de la reforma aducen como logro el incremento del aseguramiento, mientras diversas investigaciones documentan barreras de acceso y deficiente calidad de los servicios de salud, mayor segmentación representada en población aún no afiliada y en POS, diferenciales -hasta 2012- con menos servicios para la población subsidiada, desmantelamiento de la red pública de servicios, debilitamiento de la autoridad sanitaria, profundización de barreras económicas, y retroceso en indicadores de salud pública 11,12,13,14. En ese contexto, el derecho a la salud depende de la posición socio-económica. Los ajustes legislativos y los intentos regulatorios de la Corte Constitucional no han revertido esta tendencia.

Por otro lado, se ha desmantelado el frágil ESD, vía enmiendas constitucionales, recortando las transferencias de recursos para la política social a las entidades territoriales, y el alcance de la tutela para la exigibilidad de los derechos sociales ${ }^{15}$. Así, paralelamente a la profundización de reformas de mercado en los sectores sociales, se aplaza la realización de los derechos sociales como fundamentales. Ambas tendencias se implantan en un contexto histórico de violencia estructural, asociada a la pervivencia del conflicto armado, y de inequidades socioeconómicas y sanitarias.

Esa tensión ha generado la persistencia de las protestas y la emergencia de nuevos actores que disputan el campo de la salud en el período estudiado.

\section{Contienda transgresiva: concepto necesario para comprender la protesta social en salud}

Con base en Cohen et al. 16, en esta investigación definimos la acción colectiva como las protestas y movimientos sociales, producto de una experiencia compartida de malestar social, atribuible a necesidades colectivas no resueltas en el ámbito público o privado y/o a una percepción de injusticia, se construye en la interacción social, e implica visibilización y confrontación de las demandas con un adversario. La contienda política es una teoría de la acción colectiva, inscrita en la sociología histórica, propuesta por McAdam et al. ${ }^{17}$, plantea una perspectiva relacional de las interacciones entre actores colectivos -demandantes y demandados- y estructura política, pa- ra reconstruir el curso de las transformaciones sociales; reconoce asimetrías y cambios en los recursos de poder de los diferentes actores, el gobierno es una de las partes en conflicto, y la satisfacción de las demandas afecta los intereses de alguno de los contendientes.

Según los autores mencionados, la contienda es transgresiva cuando un proceso colectivo rompe el orden establecido, privilegia acciones contenciosas -públicas, frecuentemente por fuera de la institucionalidad, por ejemplo, movilizaciones, marchas, tomas de infraestructura-, es promovida por actores subalternos -con menos poder- el gobierno es uno de los adversarios, al menos uno de los actores se ha auto-identificado recientemente, y alguno de los contendientes despliega acciones colectivas innovadoras. Se puede activar cuando una transformación en el sistema político es percibida por los actores subalternos como amenaza $\mathrm{u}$ oportunidad política.

La contienda es contenida cuando los actores están previamente establecidos, utilizan repertorios consensuados, privilegiando vías institucionales -por ejemplo, debates públicos, solicitudes de amparo de un derecho ante los tribunales, presentación y/o discusión de proyectos legislativos, pronunciamientos en los medios de comunicación-; y quienes tienen mayor poder logran mantener la hegemonía y limitan la acción colectiva contenciosa. Ambas formas de contienda pueden ocurrir simultáneamente, o alguna primar en coyunturas específicas. Otras investigaciones han estudiado la contienda legislativa en Colombia 18,19.

Esta investigación reconstruye la contienda transgresiva, durante la implantación de la reforma colombiana, entre 1994 y 2010, a través de las protestas sociales por la salud, éstas, siguiendo a Archila 20 (p. 75): "Son acciones sociales de más de diez personas que irrumpen en espacios públicos para expresar intencionalmente demandas o presionar soluciones ante distintos niveles del Estado o entidades privadas"; pueden representar luchas aisladas, o un repertorio de los movimientos sociales. Las protestas pueden generar episodios de contienda, estos para McAdam et al. 17 están conformados por mecanismos y procesos, los primeros son acontecimientos delimitados -causas en pequeña escala-, y los segundos cadenas causales que entrelazan secuencias de mecanismos recurrentes, logrando mayor alcance explicativo; y, están inscritos en contextos históricos dinámicos, acotados en el tiempo. Para este trabajo, la concreción empírica de los episodios de contienda son los ciclos de protesta, definidos por Tarrow 21 (pp. 263-4) como: "Una fase de intensificación de los conflictos 
y la confrontación en el sistema social, que incluye una rápida difusión de la acción colectiva de los sectores más movilizados a los menos movilizados; un ritmo de innovación acelerado en las formas de confrontación; marcos nuevos o transformados para la acción colectiva; una combinación de participación organizada y no organizada; y unas secuencias de información e interacción intensificadas entre disidentes y autoridades que pueden terminar en la reforma, represión y, a veces en una revolución".

\section{Metodología}

Esta investigación documental se basa en fuentes primarias y secundarias para reconstruir la protesta social en salud, su contexto y la violencia anti-sindical. La información obtenida fue procesada a través del análisis de contenido. Aquí se describen las fuentes, el proceso de análisis, y los aportes y limitaciones de la metodología.

La contienda transgresiva se cuantificó reprocesando una base de datos, originalmente elaborada por el Centro de Investigación y Educación Popular, Organización No Gubernamental -ONG- que hace un seguimiento diario, a partir de la prensa nacional y regional al conjunto de protestas sociales (Centro de Investigación y Educación Popular. Base de datos sobre luchas sociales por la salud en Colombia 1994-2010). Se reclasificaron las categorías de la acción colectiva: actores, motivos, repertorios y adversarios, obteniendo 1.399 protestas sociales por la salud, entre 1994 y 2010 22, que originaron tres episodios de contienda.

El contexto socio-sanitario de la contienda transgresiva se reconstruyó con entrevistas, realizadas previo consentimiento informado, a analistas sociales y a actores convocantes y participantes de las protestas; y a través del análisis documental de prensa, de archivos personales de actores, y de fuentes secundarias. Este se utilizó en esta investigación para: (a) comprender la orientación del modelo de Estado, de política social y de salud en las dos últimas décadas en Colombia, porque los primeros análisis evidenciaron un vínculo entre protesta e implantación de reformas de mercado; (b) analizar la contienda transgresiva, y la implantación de la reforma a la salud.

Esta información se procesó mediante análisis de contenido, que es la técnica más elaborada para la investigación documental e implica un detallado proceso inductivo con un doble ejercicio hermenéutico: la interpretación que hacen de un hecho social quienes construyen un texto y la que realizamos los investigadores. El análisis de contenido deviene en la construcción de textos "densos", es decir, que relacionan la información empírica con inferencias teóricas 23 , así se reconstruyeron los mecanismos y procesos -es decir, los eventos causales- que explican los ciclos de protesta. Adicionalmente, considerando el hallazgo de los sindicatos como principales convocantes de la contienda transgresiva, y el contexto de violencia estructural colombiano, obtuvimos de otra ONG, la información sobre violaciones a los derechos humanos contra sindicalistas del sector salud en el período estudiado (Escuela Nacional Sindical. Banco de datos de derechos humanos, 2012).

Las limitaciones de la metodología fueron: (a) el subregistro, porque la prensa no documentó todas las protestas, o no reconstruyó todas las categorías de la acción colectiva; (b) los periodistas publicaron siguiendo la línea editorial del periódico y/o su propia interpretación ideológica y política. La inclusión de un periódico de oposición, las entrevistas, y la revisión de fuentes secundarias permitieron triangular y/o complementar información, y equilibrar las fuentes. El principal aporte fue el análisis de los ciclos de protesta, resultando en la primera investigación nacional sobre contienda transgresiva durante la implantación de la reforma a la salud.

\section{Resultados}

Inicia la reforma... y la protesta social: 1990-1997

Este período precede al primer ciclo de protesta, y está atravesado por: (a) la imposición del modelo de competencia regulada en salud, sobre otras dos propuestas de reforma: la del Seguro Nacional Público, del Ministerio de Salud liderado por el partido de oposición; y la de fortalecimiento del Instituto de Seguros Sociales -institución pública que integraba la atención de enfermedad, las pensiones y los riesgos laborales con un esquema de financiación solidaria y colectiva- planteada por su directora 19; (b) el inicio del proceso sistemático de reforma del Estado y de la política social, orientado a: disminuir el tamaño del Estado, profundizar la participación privada, recortar derechos sociales adquiridos, y focalizar el gasto social en la población más pobre, en el marco de las PAE; (c) una crisis de gobernabilidad que fractura la intencionalidad de matizar la apertura económica y de concretar un pacto social entre trabajadores, gobierno y empleadores; (d) una tendencia legislativa -vigente hasta hoy-, orientada a disminuir el reciente ESD pactado en la CP de 1991, representada -en esta 
coyuntura- por la reducción de aportes estatales destinados al seguro subsidiado de salud para la población pobre.

La acción colectiva en salud entre 1994-1998 giró principalmente en torno al conflicto laboral, provocado por los despidos y las políticas de flexibilización y modernización estatal, también aparecen las primeras protestas por la crisis de la red pública, debido a la transformación de los hospitales en empresas auto-sostenibles, y por la disminución de recursos para asumir las responsabilidades de la descentralización; por eso, los principales adversarios fueron, en su orden, los diferentes niveles de gobierno y los hospitales públicos y el repertorio más utilizado la huelga. En cuanto a los actores, sobresale la capacidad organizativa y de articulación sindical de los trabajadores de la salud; pobladores urbanos, y nuevas iniciativas como la Federación de Asociaciones de Usuarios de Salud, y el Movimiento Nacional por la Salud y la Seguridad Social (MNSSS) -que persiste hasta hoy-, articulando sectores académicos, organizaciones de base, ONGs, líderes y activistas sociales; se hacen visibles apoyando las reivindicaciones mencionadas o planteando las propias.

La revisión de prensa elaborada como avance del proyecto macro Acción Colectiva en Salud en Colombia, en el Contexto de la Reforma a la Salud, 1994-2010, muestra que la crisis de gobernabilidad propicia el ingreso de Ministros de Salud proclives a las reformas de mercado; el gobierno central, reacio a la negociación con los demandantes, recurre a amenazas y medidas represivas, incumple acuerdos y presenta el conflicto a la opinión pública como un problema salarial y de ineficiencia de los hospitales públicos, minimizando otras reivindicaciones estructurales de "rechazo al neoliberalismo", a los altos márgenes de intermediación de las EPS y a la focalización excluyente.

Protesta social y reforma inician simultáneamente, evidenciando tempranamente el vínculo causal entre cambio estructural de las políticas social y de salud y ACS; actores sindicales y gremiales logran articularse en las huelgas y paros nacionales, pero las demandas en salud están inmersas en otras luchas del conjunto de trabajadores del sector público. La esfera pública empieza a perfilar tendencias que permanecerán, durante las dos décadas siguientes: la débil regulación estatal frente al sector privado, la visibilidad y articulación de nuevos actores subalternos, además de los sindicatos y su rechazo a la profundización de la agenda de la reforma, la crisis hospitalaria, el poder de las EPS privadas, y la salud como nueva demanda, hasta entonces minoritaria, porque entre 1958 y 1990 apenas re- presentó, junto con la educación, el 5\% del total de luchas sociales colombianas 20 .

\section{Tres ciclos de protesta en la contienda transgresiva: 1997-2010}

La contienda transgresiva se mantiene durante todo el período de implantación de la reforma, generando tres ciclos de protesta (Figura 1), el primero entre 1997 y 2002, activado por la crisis de la red hospitalaria pública y del seguro social; el segundo, entre 2002 y 2008 es, además, contra las políticas de privatización, la disminución de recursos para la política social, las barreras de acceso a los servicios de salud, y el rechazo a la firma del Tratado de Libre Comercio con Estados Unidos. El tercero, en 2010, debido al fallido intento gubernamental de reforma al SGSSS, recurriendo a la "emergencia social", protegiendo los intereses de las EPS privadas.

\section{- Primer episodio de contienda: enfrentando la reforma del Estado y la crisis hospitalaria}

El primer episodio de contienda, entre 1997 y 2002, se convierte en el ciclo de protesta más largo; el eje de la movilización social global fue la protesta contra el Plan de Desarrollo del Presidente Pastrana, porque priorizaba la modernización del sector público y la privatización argumentando ineficiencia estatal. Ese gobierno transcurrió en una profunda crisis económica, entre 1998 y 2001, producto de las reformas de mercado implantadas desde 1990, la tasa de desempleo se duplicó, aumentaron la informalidad laboral, la pobreza y la desigualdad, y el crecimiento económico cayó al 0,5\%, disminuyendo financiación y metas de aseguramiento del nuevo SGSSS 24. Pese a este panorama económico, el gobierno profundizó las PAE: en 1999, firmó un acuerdo con el FMI, que devino en nuevas reformas e incremento de las protestas.

En la ACS, la nivelación salarial se mantuvo como motivo de lucha de los trabajadores de salud, quienes padecieron, despidos masivos, producto de la ley de ajuste al gasto público 25 , violencia antisindical -42 homicidios y 88 amenazas entre 1998-2002 a sindicalistas del sector salud- y desmantelamiento de sus organizaciones, pues las PAE flexibilizaron la contratación. No obstante, el eje del primer ciclo de protesta es la crisis hospitalaria de la red pública, ésta empieza a escalar en 1997, alcanzando máxima intensificación en 1999, y desciende a partir del 2000 después de cierres de hospitales y despidos de trabajadores en todo el país. Motivos de protesta, actores y repertorios se diversifican (Figura 2), sumando el rechazo al recorte de 
Figura 1

Acción colectiva en salud y violaciones a la vida, libertad e integridad física, contra sindicalistas del sector salud, Colombia, $1994-2010$.

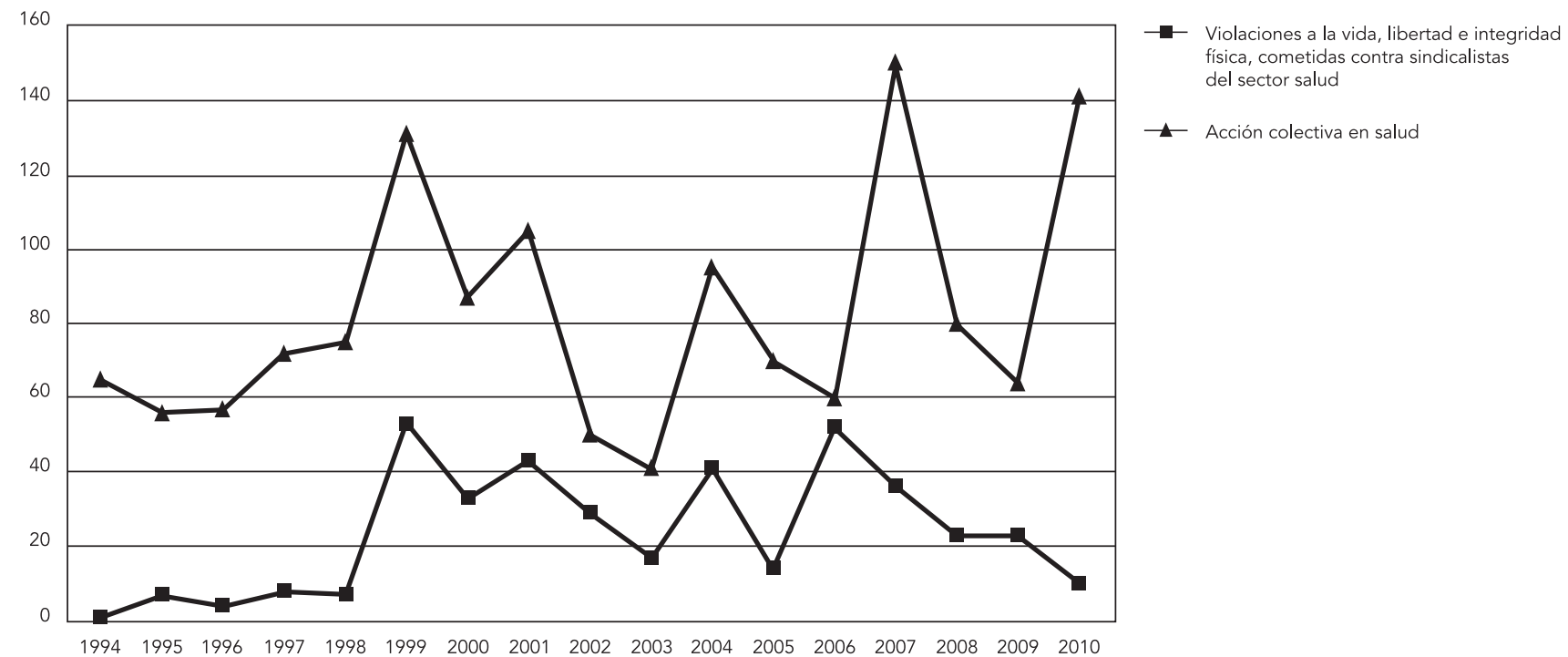

Fuente: Acción colectiva: base de datos cuantitativa, basada en la información del Centro de Investigación y Educación Popular (CINEP). Procesada por: Borrero et al. 22. Proyecto COLCIENCIAS. Contrato RC n. 309 de 2011. Violencia anti-sindical: banco de datos de Derechos Humanos, SINDERH, Escuela Nacional Sindical.

Figura 2

Motivos de la acción colectiva en salud en Colombia, 1994-2010.
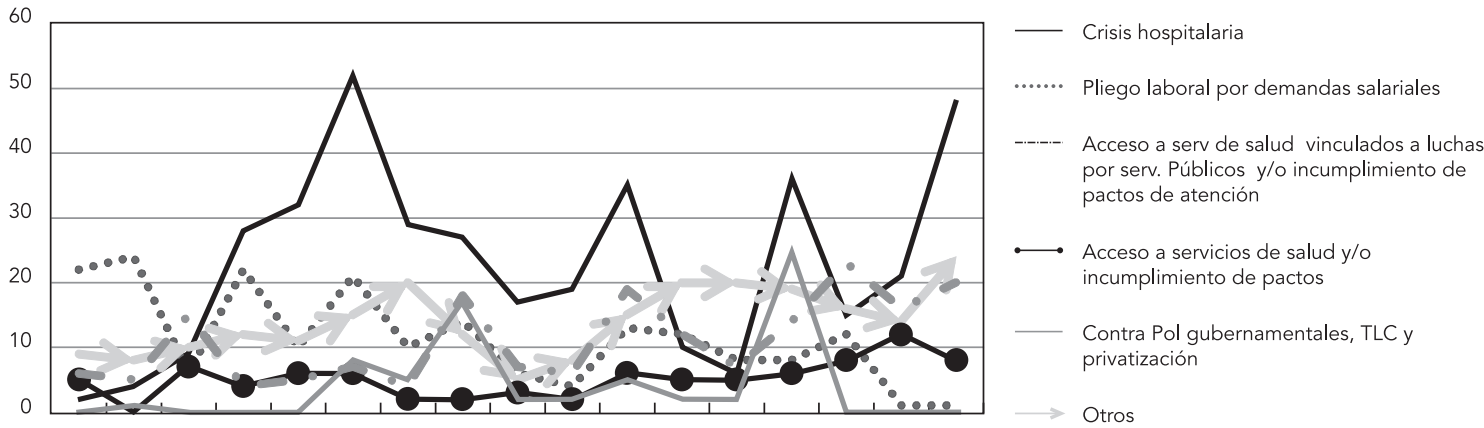

19941995199619971998199920002001200220032004200520062007200820092010

Fuente: base de datos cuantitativa, basada en la información del Centro de Investigación y Educación Popular (CINEP). Procesada por: Borrero et al. 22. Proyecto COLCIENCIAS. Contrato RC n. 309 de 2011.

transferencias de la nación a las entidades territoriales 26 -porque implicaba menos recursos para la política social y dejar de afiliar, entre 5 y
6 millones de pobres, al seguro subsidiado- 27; y

al "paseo de la muerte" -pacientes, generalmente pobres, que transitan entre instituciones, sin 
recibir atención, hasta fallecer-, resultado extremo de las barreras de acceso a los servicios. Los estudiantes universitarios convergen en las protestas por la crisis hospitalaria; mujeres, población reclusa, y organizaciones indígenas y campesinas reivindican necesidades particulares, ampliando el ámbito del derecho a la salud y visibilizando los efectos adversos de la reforma.

El gobierno no actúa para evitar el declive de los hospitales y de las EPS públicas, en contraste, destina cuantiosos recursos para salvar la banca. Este escenario afianza el poder del capital privado en salud agremiado en un nuevo actor: la Asociación Colombiana de Empresas de Medicina Integral (ACEMI). El diálogo se concentra en las negociaciones con la guerrilla, relegando las demandas de la protesta social y las evidencias de otros actores gubernamentales como la Defensoría del Pueblo y la Corte Constitucional, cuyas investigaciones denunciaban la escasa regulación estatal y las violaciones al derecho a la salud, mientras la jurisprudencia protegía ese derecho, vía tutela, más allá del POS.

\section{- Intensificación y autonomía de las protestas por la salud: 2006-2010}

Entre 2002 y 2010 llega al gobierno Álvaro Uribe, quien como parlamentario había liderado, a principios de los noventa, las reformas, laboral, de salud y de seguridad social. Él profundiza las transformaciones institucionales introduciendo el enfoque de Manejo Social del Riesgo, propuesto por el BM, así la acción estatal solo cabe cuando individuo, familia y comunidad no resuelven los riesgos en el mercado 8 . En consecuencia, realiza segundas reformas en los ámbitos laboral -2002-; y a las transferencias y la salud en 2007. La política económica favorece a los sectores de mayores ingresos, generando un crecimiento "pro-rico" 28. En cuanto al conflicto, formula una controvertida política de "seguridad democrática”, promoviendo pagos por delación de supuestos integrantes de grupos vinculados al conflicto político armado; inicia negociaciones con los grupos paramilitares; y arrecia la confrontación con la guerrilla.

La contienda transgresiva en salud se mantiene: desciende en 2002 y 2003 a las cifras más bajas del período, por los despidos y el desmantelamiento sindical resultantes de la primera ola de reformas laboral y hospitalaria, disminuye la participación de trabajadores y sindicatos de salud, quienes, hasta entonces, habían sido los mayores convocantes y participantes de las protestas. Éstas se incrementan de nuevo en 2004, por la agudización de la crisis hospitalaria: a los efectos de las reformas mencionadas, se suma una deuda de 1.400 millones de dólares, porque los agentes del SGSSS, especialmente las EPS retienen pagos buscando mayor rentabilidad; y continúan las protestas por la negociación del TLC con Estados Unidos y por los "paseos de la muerte" 19.

Entre 2004 y 2006, el gobierno promueve una reforma a la Ley $n$. 100/93, diversos actores presentan numerosos proyectos de ley; algunos sindicatos y el MNSSS, en coalición con el partido de oposición proponen una reforma estructural, basada en el derecho fundamental a la salud, pero son derrotados en la contienda legislativa, donde se impone la propuesta gubernamental -Ley n. 1.122/07 de 2007-, ésta aumenta la afiliación al seguro subsidiado y propone un Plan Nacional de Salud Pública, pero mantiene las EPS privadas, la segmentación, y las barreras de acceso 29. Esta contienda también muestra las dificultades de los actores subalternos para articularse.

La segunda reforma a las transferencias 30 , las nuevas re-estructuraciones, cierres y privatizaciones de los hospitales públicos y la escisión y privatización del seguro social, detonan el segundo ciclo de protesta entre 2007 y 2008. La contienda transgresiva alcanza la máxima intensificación de todo el período -150 acciones colectivas en 2007- (Figura 1), antecedida por el incremento de la violencia contra sindicalistas del sector salud -39 amenazas y 56 acciones violentas. Estos disminuyen su participación, pero hay mayor consenso en torno a una reforma estructural al SGSSS: organizaciones gremiales y de usuarios, indígenas y pobladores urbanos, convergen con otros actores en la defensa conjunta de los sectores más afectados -educación y salud- con el recorte a las transferencias.

La continuidad de la crisis y de las protestas evidencia la ineficacia de la Ley n. 1.122/07, la Defensoría del Pueblo anuncia incremento sostenido de las tutelas desde 1999, y la Corte Constitucional emite la Sentencia de Tutela -ST n. 760/08 de 2008-, impartiendo órdenes al Estado, EPS y otras instancias del SGSSS, para el cumplimiento de regulaciones ya previstas en las normas -la homologación del POS, remoción de barreras de acceso y entrega de servicios no-POS. Este pronunciamiento suscitó inconformidad en el ejecutivo y en las EPS que aducían insuficiencia de recursos, mientras otros actores -academia, MNSSS y algunos sindicatos- lo consideraban ambiguo, porque la corte declaraba a la salud como derecho fundamental autónomo, y simultáneamente invocaba la sostenibilidad financiera 31 .

Aunque arreciaban las denuncias por corrupción y desviación de dineros públicos para el lucro de las EPS privadas 32, el Gobierno Nacional, argumentando una crisis financiera so- 
breviniente en el SGSSS, expide, en diciembre de 2009, un conjunto de decretos, utiliza un recurso excepcional para declarar la emergencia social en salud. Ésta otorga facultades legislativas al Presidente, omitiendo el debate parlamentario, es presentada al país como necesaria para cumplir las órdenes de la $S T n$. 760/08, y para resolver la iliquidez del SGSSS, generada por servicios no-POS. Los decretos más polémicos establecían que estos fueran pagados por los usuarios, con cesantías, y ahorros personales o familiares, y limitaban la autonomía médica 33 .

Las medidas provocaron indignación y desataron, además de un amplio debate nacional, un tercer episodio de contienda transgresiva en 2010 con el mayor número de ACS -141- después de las 150 observadas en 2007. Abundaron repertorios no contenciosos -demandas de inconstitucionalidad, y pronunciamientos académicos-; sin embargo, la articulación de sindicatos, movimientos cristiano y estudiantil, MNSSS, y de nuevos actores -grupos de pacientes de diferentes patologías- protagonizaron movilizaciones sociales sin precedentes, innovando repertorios, como la convocatoria por las redes sociales, y reivindicando la salud como derecho fundamental ${ }^{19}$. Se evidenciaron: (a) la intencionalidad del ejecutivo de favorecer los intereses rentísticos de las EPS, que amenazaron con cerrarse sí no les pagaban los servicios no-POS; (b) las tensiones del ejecutivo con los actores subalternos, el partido político opositor que proponía cambio estructural del SGSSS; y la Corte Constitucional, que por unanimidad, declaró inexequibles la mayoría de los decretos de la emergencia social; y, (c) la capacidad de movilización de los actores subalternos quienes por primera vez ganaron la contienda.

Los dos últimos episodios de contienda consolidaron las tendencias perfiladas desde el inicio de la reforma: profundización de la agenda de reformas de mercado en salud, de la judicialización de líderes y de la violencia anti-sindical; y acción gubernamental proclive a los intereses del capital privado, acompañada de talante autoritario, negligente ante el sufrimiento generado por la crisis de la salud y el despojo de lo público, e indiferente a la protesta social. Sin embargo, la pluralidad de actores subalternos logra mayor articulación e identidad propia -autónoma respecto a otras luchas- en la coyuntura de la emergencia social.

\section{Conclusiones}

La acción colectiva en salud en Colombia en las dos últimas décadas está atravesada por la dispu- ta entre dos concepciones antagónicas acerca del papel social del Estado, la hegemónica, puesta en marcha con la reforma a la salud iniciada en 1993, basada en la privatización, el desmantelamiento de la institucionalidad pública, y en la realización segmentada del derecho a la salud, según posición socioeconómica; y la más débil, sustentada en el ESD de la Constitución de 1991, y en la garantía del derecho fundamental a la salud, cuyo desmantelamiento ha sido paralelo a la consolidación de la agenda de la reforma. Cada tendencia ha sido defendida por actores específicos: la de la reforma por el ejecutivo y las mayorías parlamentarias, por el gremio de las EPS privadas, y por algunos sectores académicos; la del derecho fundamental a la salud, por la Corte Constitucional, la Defensoría del Pueblo, el MNSSS, otro sector de la academia, y se ha configurado como elemento identitario de las luchas de los actores subalternos.

La contienda transgresiva entre 1994 y 2010, reconstruida con una investigación documental, evidencia el vínculo causal entre protesta social en salud e implantación de la reforma: 3 episodios de contienda coinciden con los ciclos de protesta, y se intensifican, paralelamente a la violencia antisindical, con la puesta en marcha de políticas sociales y de salud orientadas al mercado. La crisis hospitalaria y el despojo de derechos laborales detonaron la mayoría de las luchas del período, pero los motivos transitaron de reivindicaciones laborales a demandas generales -oposición al Tratado de Libre Comercio con Estados Unidos, al recorte de recursos de política social y a la violencia antisindical-; y a la defensa del derecho fundamental a la salud, visible a partir de la emergencia social. En consecuencia, el principal adversario fue el gobierno en sus diferentes niveles.

Los principales convocantes de las protestas fueron los sindicatos, quienes disminuyen su participación desde 2002, producto de la violencia, los despidos y la flexibilización laboral. Los participantes mayoritarios fueron trabajadores de la salud, y pobladores urbanos. Sin embargo, desde 1998 se empieza a conformar un MNSSS, aún vigente; y, desde 2002, se diversifican actores, motivos y repertorios: pobladores urbanos, estudiantes y organizaciones de usuarios, recurren a Internet y participan en el debate legislativo. El gobierno -ejecutivo y Congreso- favoreció los intereses rentísticos de las EPS, pese al intento regulatorio de la Corte Constitucional con la $S T$ $n$. 760/08 y a las denuncias de violaciones sistemáticas del derecho a la salud de la Defensoría del Pueblo; enfrentó la ACS, moviéndose entre la resistencia a la negociación, la represión, el desconocimiento y estigmatización de las protestas, 
el incumplimiento de pactos, la impunidad frente a la violencia anti-sindical, y la judicialización de líderes sociales.

La contienda transgresiva no modificó la agenda de la reforma, excepto en la coyuntura de la emergencia social, pero ha reconfigurado la esfera pública: sobresale la articulación de actores visible en los momentos de intensificación de la protesta y las iniciativas y repertorios no contenciosos -por ejemplo, la contienda legislativa- que hablan de inversión organizativa y fortalecimiento de "redes sumergidas". Estas luchas han contribuido al surgimiento de nuevos actores, a la construcción de un MNSSS, a visibilizar los efectos adversos de las reformas sociales neoliberales, y a comprender la lucha por el derecho fundamental a la salud como un asunto estratégico. Hay avances en la configuración de un sujeto colectivo, a pesar de la persistencia de la violencia y de la escasa apertura del sistema político. Queda la pregunta de por qué la salud, asunto nuevo en la arena política, no tiene una mayor resonancia social.

\section{Resumo}

Esta pesquisa documental reconstrói a competição transgressiva em saúde na Colômbia durante a execução da reforma da saúde, entre 1994 e 2010, com base na análise de fontes primárias e secundárias. Tem como aproximação teórica a contenda política, uma teoria da ação coletiva com perspectiva relacional entre atores coletivos e estrutura política para entender as transformações históricas. Três episódios de contenda são reconstruídos; demonstram uma relação de causalidade entre protestos e as reformas estruturais da política social e de saúde. As lutas dos atores subalternos mostraram a desapropriação dos direitos trabalhistas, a crise dos hospitais públicos e as barreiras de acesso a serviços; como efeitos adversos da reforma, o governo favoreceu os interesses do capital privado. Os protestos persistiram apesar da violência antissindical e de repressão do governo, novos atores e um movimento nacional de saúde reformularam a esfera pública, a construção de identidade em torno da luta pelo direito fundamental à saúde.

Direito à Saúde; Reforma dos Serviços de Saúde; Política de Saúde

\section{Nota final}

Después de esta investigación, la disputa por la salud continúa en Colombia, actualmente hay una fuerte contienda con amplias protestas contra las iniciativas legislativas gubernamentales, porque mantienen el modelo de mercado en salud y la intermediación de las EPS privadas, y no plantean soluciones a las recurrentes crisis hospitalarias y a la persistencia de las violaciones al derecho a la salud. Se ha conformado una Alianza Nacional por la Salud que ha presentado proyectos de ley alternativos orientados a una reforma estructural del SGSSS, basada en el derecho fundamental a la salud; allí convergen actores subalternos formados en las luchas por la salud de estas dos décadas, pero persisten los retos mencionados.

\section{Colaboradores}

M. E. Echeverry-López investigadora principal del proyecto, en el que se basó este artículo, participó en la elaboración del informe de esta investigación, basándose en archivos de prensa, síntesis de los tres episodios de contienda, así como en los ajustes y revisión final. Y. E. Borrero-Ramírez colaboró en la construcción de la propuesta de investigación, diseño teórico y metodológico del trabajo, desarrollo y revisión crítica, así como en la aprobación del artículo y correcciones realizadas.

\section{Agradecimientos}

Agrademos al Departamento Administrativo de Ciencia, Tecnología e Innovación Colombiano su apoyo financiero; al Grupo de Investicación, Gestión y Políticas de Salud, Línea de Investigación "Derecho a la Salud y Luchas Sociales por la Salud en Colombia de la Facultad Nacional de Salud Pública de la Universidad de Antioquia y a la Pontificia Universidad Javeriana de Cali por su apoyo para la realización de este proyecto; a la Escuela Nacional Sindical de Medellín por la información sobre violencia antisindical del sector salud; a Liliana García, Dayan Ocampo, Ruby Milena Paja y Alejandra Marín por el apoyo académico y logístico. 


\section{Referencias}

1. Almeida C. Reforma del sector salud y equidad en América Latina y el Caribe: conceptos, agenda, modelos y algunos resultados de implementación. Rev Gerenc Políticas Salud 2005; 9:6-60.

2. Londoño JL, Frenk J. Structured pluralism: towards a new model for health system reform in Latin America. Washington DC: World Bank; 1995.

3. Laurell A. La reforma contra la salud y la seguridad social: una mirada crítica y una propuesta alternativa. México DF: Era; 1997.

4. Ahumada C, Uribe C. Reformas del Estado y políticas de salud en Colombia: un enfoque de salud internacional. Bogotá: Pontificia Universidad Javeriana; 1999.

5. Williamson J. El cambio en las políticas económicas de América Latina. México DF: Ediciones Gernika; 1991.

6. Banco Mundial. El financiamiento de los servicios de salud en los países en desarrollo. Una agenda para la reforma. Bol Oficina Sanit Panam 1987; 103:695-709.

7. Banco Mundial. Invertir en salud. Informe del desarrollo mundial. Washington DC: Banco Mundial; 1993.

8. Holzmann R, Jorgensen S. Manejo social del riesgo: un nuevo marco conceptual para la protección social y más allá. Washington DC: Banco Mundial; 2000.

9. Congreso de la República de Colombia. Ley n. 100 de 1993. Por la cual se crea el Sistema de Seguridad Social Integral y se dictan otras disposiciones. Bogotá: Congreso de la República de Colombia; 1993.

10. Arango R. Constitucionalismo, Estado Social de Derecho y realización integral de los derechos. In: Arango R, editor. Derechos, constitucionalismo y democracia. Bogotá: Universidad Externado de Colombia; 2004. p. 59-93.

11. Abadía C, Oviedo D. Bureaucratic itineraries in Colombia: a theoretical and methodological tool to assess managed-care health care systems. Soc Sci Med 2009; 68:1153-60.

12. Paredes N. A cinco años de la reforma al sistema de salud colombiano ¿Qué ha pasado con el derecho a la salud? In: De Currea Lugo V, Hernández, M, Paredes N, editores. La salud está grave, una visión desde los derechos humanos. Bogotá: Plataforma Colombiana de Derechos Humanos, Democracia y Desarrollo; 2000. p. 165-87.

13. Echeverry ME. El derecho a la salud en Medellín, Colombia, desde la perspectiva de los usuarios, en el contexto de la reforma: 1990-2006. México DF: Universidad Autónoma Metropolitana; 2008.

14. Yepes F, Ramírez M, Sánchez LH, Ramírez M, Jaramillo I. Luces y sombras de la reforma de la salud en Colombia: Ley n. 100 de 1993. Bogotá: Mayol Ediciones; 2010.
15. Echeverry ME. Indignación justa: estudios sobre la acción de tutela en salud en Medellín. Medellín: Universidad de Antioquia; 2013.

16. Cohen J, Touraine A, Melucci A, Jenkins J. Teoría de los movimientos sociales. Cuadernos de Ciencias Sociales 1988; (17):3-42.

17. McAdam D, Tarrow S, Tilly C. Dynamics of contention. Cambridge: Cambridge University Press; 2001.

18. Uribe M. ¿Mercado regulado o competencia sin control?: las reformas de la salud en Colombia, 1995-2011. In: Uribe M, editor. Los vaivenes de las políticas sociales en Argentina, Colombia, Chile, México y Uruguay. ¿̇Neo o posneoliberalismo? México DF: Editorial Porrúa; 2011. p. 33-80.

19. Borrero Y. Luchas por la salud en Colombia 19942011: hacia la construcción de un movimiento nacional por la salud. Medellín: Universidad de Antioquia; 2013.

20. Archila M. Idas y venidas, vueltas y revueltas: protestas sociales en Colombia, 1958-1990. Bogotá: Instituto Colombiano de Antropología e Historia/Centro de Investigación y Educación Popular; 2005.

21. Tarrow S. El poder en movimiento: los movimientos sociales, la acción colectiva y la política. Madrid: Alianza Editorial; 1997.

22. Borrero Y, Ocampo D, Paja R. Base de datos cuantitativa sobre acción colectiva por la salud en Colombia 1994-2010, con base en la información de Centro de Educación e Investigación Popular. Bogotá: Universidad de Antioquia; 2011.

23. Galeano ME. Estrategias de investigación social cualitativa: el giro en la mirada. Medellín: La Carreta Editores; 2004.

24. Garay L. Colombia: entre la exclusión y el desarrollo. Propuestas para la transición hacia el Estado Social de Derecho. Bogotá: Contraloría General de la República; 2002.

25. Congreso de la República de Colombia. Ley n. 617 de 2000. Por la cual se reforma parcialmente la Ley 136 de 1994, el decreto extraordinario 1222 de 1986, se adiciona la Ley Orgánica de presupuesto, el Decreto n. 1.421 de 1993, se dictan otras normas tendientes a fortalecer la descentralización y otras para racionalización del gasto público nacional. Bogotá: Congreso de la República de Colombia; 2000.

26. Congreso de la República de Colombia. Ley n. 715 de 2001. Por la cual se dictan normas orgánicas en materia de recursos y se dictan otras disposiciones para organizar la prestación de los servicios de educación y salud, entre otros. Bogotá: Congreso de la República de Colombia; 2001.

27. Sandoval M. Lo que finalmente quedó de las transferencias. Bogotá: Corporación Viva la Ciudadanía; 2007. 
28. González JI. Más inversión, más pobreza y más desigualdad. Cien Días 2010; 7:31-3.

29. Congreso de la República de Colombia. Ley n. 1.122 de 2007. Por la cual se hacen algunas modificaciones en el Sistema General de Seguridad Social en Salud y se dictan otras disposiciones. Bogotá: Congreso de la República de Colombia; 2007.

30. Congreso de la República de Colombia. Ley n. 1.176 de 2007. Por la cual se desarrollan los artículos 356 y 357 de la Constitución Política y se dictan otras disposiciones. Bogotá: Congreso de la República de Colombia; 2007.
31. Corte Constitucional. Sentencia ST n. 760 de 2008. Bogotá: Corte Constitucional; 2008.

32. León J. El Consenso de ACEMI: el acuerdo de las EPS para negar servicios de salud. Bogotá: La Silla Vacía; 2011.

33. Presidencia de la República de Colombia. Decreto n. 4.975 de 2009. Por el cual se declara el Estado de Emergencia Social. Bogotá: Presidencia de la República de Colombia; 2009.

Recibido el 24/Feb/2014

Aprobado el 29/Ago/2014 